\title{
Influence of Al and Ti Additions on Microstructure and Mechanical Properties of Leaded Brass Alloys
}

\author{
Rajab Mohammed Hussein ${ }^{1}$ and Osama Ibrahim Abd ${ }^{2}$ \\ ${ }^{1}$ Mechanical Engineering Department, University of Al-Anbar, Ramadi, Iraq \\ ${ }^{2}$ Renewable Energy Research Center, University of Al-Anbar, Ramadi, Iraq \\ Correspondence should be addressed to Osama Ibrahim Abd; osama_eng21@yahoo.com
}

Received 13 April 2014; Revised 1 June 2014; Accepted 5 June 2014; Published 16 July 2014

Academic Editor: Debdulal Das

Copyright (c) 2014 R. M. Hussein and O. I. Abd. This is an open access article distributed under the Creative Commons Attribution License, which permits unrestricted use, distribution, and reproduction in any medium, provided the original work is properly cited.

Brass has an attractive combination of properties, namely, good corrosion resistance, good wear properties, and high thermal and electrical conductivity. In this study, influence of selected alloy additions ( $\mathrm{Al}$ and $\mathrm{Ti}$ ) on performance of leaded brass alloys (CuZn39pb3) was investigated. The observation of microstructures, compression tests, and hardness tests were performed. The results of metallographic and mechanical tests indicate some influence of small amount additives of $\mathrm{Al}$ and Ti. Optical emission spectrometer (OES), light optical microscope (LOM), micro-Vickers hardness tester, and compression testing machine were used in this investigation. Consequently, $\mathrm{Al}$ had a significant effect on microstructure and mechanical properties of $\mathrm{CuZn} 39 \mathrm{~Pb} 3$ alloy. A larger compression strength at $0.31 \%$ wt of $\mathrm{Al}$ was obtained, as compared with the other alloys. Adding of $\mathrm{Al}$ and $\mathrm{Ti}$ led to the modification of the microstructure; thus, the compression strength was increased.

\section{Introduction}

$\mathrm{Cu}-\mathrm{Zn}$ alloy is widely used as an industrial material because of its excellent characteristics such as high corrosion resistance, nonmagnetism, and good machinability. In particular, machinable brass is obtained by adding lead [1]. High copper contents (larger than 60\%) are needed to produce products by cold working in order to have a good enough formability. When a good machining behaviour is required, lead is added (until 3\%). The benefits conferred by the presence of lead have been appreciated for many years to facilitate chip fracture, reduce cutting forces, increase the machining rate and productivity, reduce tool wear, and enhance surface finish [2].

Major improvements in performance occur when the structure changes from all-beta to alpha + beta [duplex] and from duplex to all-alpha phase. Alloys containing less than $15 \% \mathrm{Zn}$ are rarely dezincified. Some alloying additions have a large effect on the structure of brass, by altering the proportion of alpha, beta, or gamma phase present [3]. Alloying elements are added as solid solution strengtheners like $\mathrm{Al}, \mathrm{Mn}$, and $\mathrm{Fe}$; these additives lead to the increase of the area fraction of hard $\beta$-phase. However, when these strengtheners are added with large amounts, the coarser and brittle intermetallic compounds form the matrix, and the drastic decrease occurs. Hence, brass alloys require to be strengthened by small amounts of additives to decrease the content of intermetallic compounds (IMCs) and disperse fine in the matrix [4].

Grain refiners are materials added to alloys to aid in nucleation and lead to the production of fine and uniform grain sizes [5]. Grain size has a measurable effect on most mechanical properties. For example, at room temperature, hardness, yield strength, tensile strength, fatigue strength, and impact strength all increase with decreasing grain size [6]. From the earlier work with various alloys and grain refiners, it is well known that boron refines the yellow brass, boron or zirconium refines Enviro Brass III depending on the tin content, and zirconium (added as sponge zirconium) refines the copper alloys containing silicon [7].

In this investigation, those experiments were conducted using brass alloys with very low levels of Aluminum and Titanium. Hence, it will be interesting to evaluate the effect 
of Aluminum on grain refinement of microstructure and mechanical properties of $\mathrm{CuZn39Pb3}$ brass alloy.

\section{Experimental Work}

2.1. Alloy Preparation. About $0.5 \mathrm{~kg}$ of CuZn39Pb3 brass alloy was prepared using high purity copper (99.99\%). For each experiment, copper was added in a clay-graphite crucible of $1 \mathrm{~kg}$ capacity and melted using a gas furnace. Both of Zinc and Lead were warped by aluminum foils and added into the melt. About $5 \%$ of $\mathrm{Zn}$ and $5 \%$ of $\mathrm{Pb}$ were added to compensate their loss, due to vaporization at temperatures relatively close to the melting point [8]. The melt was subjected to fluxing and degassing using commercially available fluxes and degassing tablets, respectively. The melt was stirred by using graphite rod to achieve the melt homogeneity. After stirring, the melt was held in the furnace for sufficient time. Then, the melt was poured at $980^{\circ} \mathrm{C}$ in steel mold that was preheated at $500^{\circ} \mathrm{C}$ in order to avoid sticking of molten alloy and to facilitate a trouble-free melt flow. Cylindrical samples with the diameter of $18 \mathrm{~mm}$ and the height of $200 \mathrm{~mm}$ were produced. Additional amounts of $\mathrm{Al}$ and $\mathrm{Ti}$ were added during the melting to study their effect on microstructure of the alloy.

2.2. Microstructural Tests. For microstructural study, the cast samples were cut into disc shape $18 \mathrm{~mm}$ in diameter and $5 \mathrm{~mm}$ thick from a bar of different alloys prepared. All of the specimens were ground through $220,320,500,800$, and 1000 grit silicon carbide papers. Then, they were polished up to $1 \mu \mathrm{m}$ diamond paste and cleaned with alcohol and etched by solution of $25 \mathrm{~mL}$ of $\mathrm{HCl}, 25 \mathrm{~g}$ of $\mathrm{FeCl}_{3}$, and $100 \mathrm{~mL}$ of water. The microstructural images of the specimens were observed by using an optical microscope (XJP-6A), equipped with CANON digital camera. The test was done at 500x magnification. Then, the J-Image software was used to analyze the microstructural images.

2.3. Mechanical Tests. Compression test was carried out using cylindrical specimens with the diameter of $18 \mathrm{~mm}$ and the height of $15 \mathrm{~mm}$, machined coaxially to the long bar direction. $200 \mathrm{KN}$ load capacity, 9-500 $\mathrm{mm} / \mathrm{mint}$ speed rate, wdw-200e universal testing machine was used. Furthermore, microVickers hardness tests were also performed on the crosssection of the specimens using a Qualitest/model QV-1000 testing machine. At least three readings were taken for each sample to obtain the average value. The used load was $100 \mathrm{gf}$ for dwell time of 15 seconds.

\section{Results and Discussion}

Various types of brass alloys were prepared for different experiments. The chemical composition of these prepared alloys is included in Table 1. Chemical composition analysis was performed by optical emission spectrometer (OES).

3.1. Microstructural Observation. The effect of various alloying additions on the microstructure of $\mathrm{CuZn} 39 \mathrm{~Pb} 3$ is not well understood. Also the interaction between the grain refiner

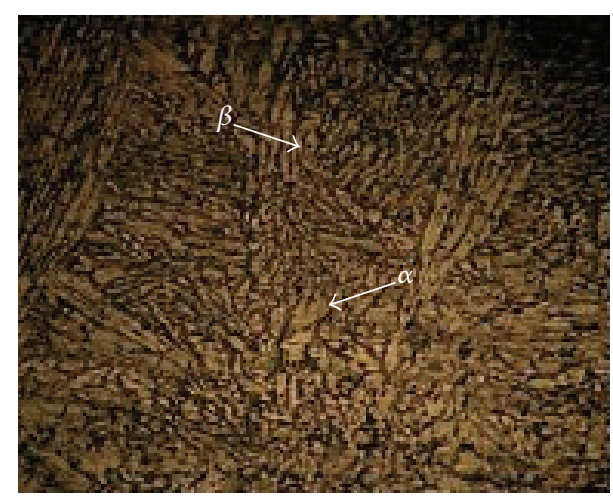

Figure 1: The microstructure of base CuZn39Pb3 alloy (Code 0) at 500x.

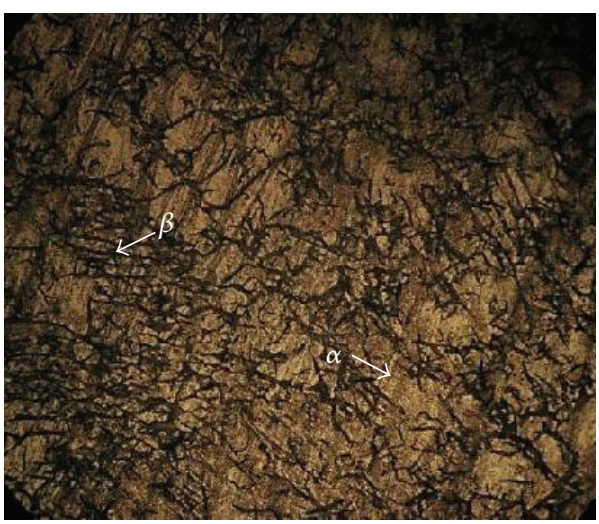

FIgURE 2: The microstructure of CuZn39Pb3 alloy after addition of $0.28 \% \mathrm{Al}$ (Code 1$)$ at $500 \mathrm{x}$.

and minor alloying additions such as $\mathrm{Al}$ and $\mathrm{Ti}$ should be evaluated. The results including the analysis of the prepared brass alloys to study the effect of alloying elements on the microstructure of $\mathrm{CuZn} 39 \mathrm{~Pb} 3$ are shown in Table 1. The microstructure of the base $\mathrm{CuZn} 39 \mathrm{~Pb} 3$ alloy is presented in Figure 1.

The base $\mathrm{CuZn39Pb3}$ alloy has a coarse grain and dendritic structure, contains primary $\alpha$ dendrites with some $\beta$ phase in the interdendritic and grain boundaries. Every other element added to this alloy modifies the structure in both constituents and size.

In this work, the CuZn39Pb3 alloy after addition of $0.28 \%$ $\mathrm{Al}$ and $0.31 \% \mathrm{Al}$ still has a coarse and dendritic structure as shown in Figures 2 and 3, respectively. But the dendrites are larger and well distinct. The grain size (Table 2), in these cases, is also larger as compared with base alloy (Code 0). García et al. confirmed that the Al has a significant effect on grain size, when $0.25 \% \mathrm{Al}$ was added to $\mathrm{Cu}-\mathrm{Zn}-\mathrm{Sn}$ brass alloy (free of boron), and the grain size rating increased from 2 to $4.5[2]$.

After an addition of $0.5 \% \mathrm{Al}$ and $0.54 \% \mathrm{Al}$, the microstructure shows a marginal decrease in grain size (Table 2), while clear needles are observed in Figures 4 and 5 , respectively. The grains are columnar and have matrix 
TABLE 1: Chemical composition of brass alloys.

\begin{tabular}{lccccccccccccccc}
\hline \multirow{2}{*}{ Alloy code } & \multicolumn{1}{c}{} & $\mathrm{Cu}$ & $\mathrm{Zn}$ & $\mathrm{Pb}$ & $\mathrm{Al}$ & $\mathrm{Bi}$ & $\mathrm{Fe}$ & $\mathrm{Sn}$ & $\mathrm{Cd}$ & $\mathrm{Ni}$ & $\mathrm{Si}$ & $\mathrm{Sb}$ & $\mathrm{Mg}$ & $\mathrm{Mn}$ & $\mathrm{Ti}$ \\
\hline 0 & 60.07 & Rem. & 3.03 & 0.024 & 0.01 & 0.12 & 0.005 & 0.001 & 0.31 & 0.00 & 0.017 & 0.001 & 0.003 & - \\
1 & 63.34 & Rem. & 2.75 & 0.28 & 0.006 & 0.06 & 0.000 & 0.000 & 0.04 & 0.00 & 0.007 & 0.001 & 0.005 & - \\
2 & 61.8 & Rem. & 5.24 & 0.31 & 0.006 & 0.08 & 0.006 & 0.000 & 0.21 & 0.00 & 0.005 & 0.000 & 0.002 & - \\
3 & 57.41 & Rem. & 4.36 & 0.5 & 0.009 & 0.08 & 0.000 & 0.000 & 0.035 & 0.006 & 0.02 & 0.000 & 0.005 & - \\
4 & 60.34 & Rem. & 3.27 & 0.54 & 0.01 & 0.12 & 0.02 & 0.001 & 0.49 & 0.00 & 0.01 & 0.000 & 0.00 & - \\
5 & 58.8 & Rem. & 2.7 & 0.96 & 0.01 & 0.21 & 0.13 & 0.003 & 0.068 & 0.13 & 0.02 & 0.001 & 0.00 & - \\
6 & 59.96 & Rem. & 4.09 & 0.28 & 0.00 & 0.09 & 0.02 & 0.002 & 0.31 & 0.00 & 0.013 & 0.000 & 0.000 & 0.93 \\
\hline
\end{tabular}

TABLE 2: The mechanical properties of the studied alloys.

\begin{tabular}{|c|c|c|c|c|c|}
\hline Alloy code & $\begin{array}{c}\mathrm{Al} \\
\% \mathrm{wt}\end{array}$ & Max. compression load (KN) & Deformation (mm) & Hardness (HV) & Grain size $(\mu \mathrm{m})$ \\
\hline 0 & 0.024 & 100.64 & 4.1887 & 47.9 & 9.57 \\
\hline 1 & 0.28 & 96.56 & 4.7875 & 45.82 & 10 \\
\hline 2 & 0.31 & 103.92 & 4.79 & 44.93 & 13.35 \\
\hline 3 & 0.5 & 94.52 & 3.5975 & 52.06 & 8.88 \\
\hline 4 & 0.54 & 95.32 & 4.0763 & 54.10 & 8.38 \\
\hline 5 & 0.96 & 97.52 & 3.1962 & 53.90 & 8.7 \\
\hline 6 & $\begin{array}{c}0.28+0.93 \% \\
\mathrm{Ti}\end{array}$ & 101.28 & 4.3962 & 49.26 & 9.51 \\
\hline
\end{tabular}

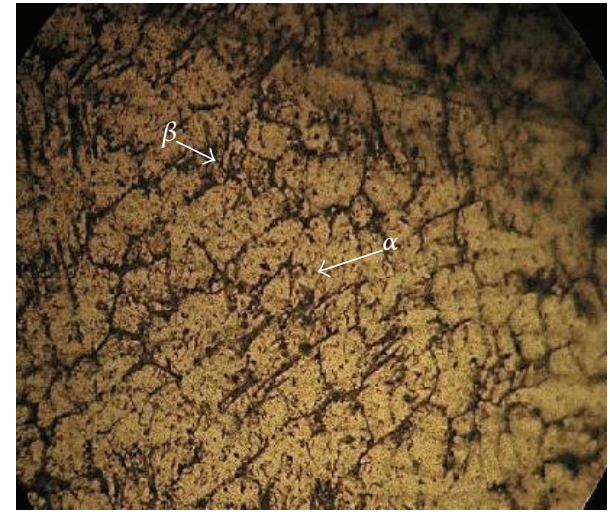

Figure 3: The microstructure of $\mathrm{CuZn} 39 \mathrm{~Pb} 3$ alloy after addition of $0.31 \% \mathrm{Al}$ (Code 2) at $500 \mathrm{x}$.

containing mainly $\beta$-phase with $\alpha$ needles dispersed within the matrix.

The grain size of the alloy after $0.96 \% \mathrm{Al}$ adding seems to be reduced as shown in Figure 6 and Table 2. The grain size in this case is very fine compared to the base $\mathrm{CuZn} 39 \mathrm{~Pb} 3$ alloy. However, a ring of columnar grains could be still observed in the outer surface indicating lack of grain refinement in this alloy. The microstructure is also very fine.

The microstructure of samples from the experiments, after addition of $0.28 \% \mathrm{Al}$ and $0.93 \% \mathrm{Ti}$, is presented in Figure 7. After adding both of these alloying elements $\mathrm{Al}$ and $\mathrm{Ti}$, the grain size is marginally reduced and more uniform, but the structure remains dendritic, as compared with base CuZn39Pb3 structure (Code 0) and alloy (Code 1).

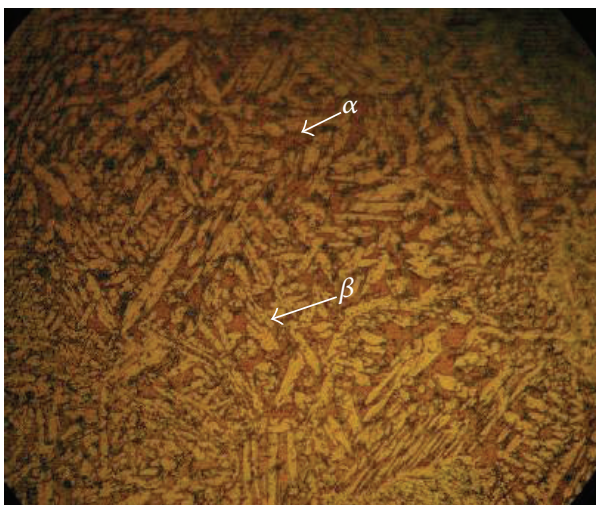

FIgURE 4: The microstructure of CuZn39Pb3 alloy after addition of $0.5 \% \mathrm{Al}($ Code 3$)$ at $500 \mathrm{x}$.

Appon et al. show that Aluminum is known as a promoter of $\beta$-phase in $\mathrm{Cu}$ - $\mathrm{Zn}$ alloys and is considered at least 6 times effective than $\mathrm{Zn}$. In other words, $1 \% \mathrm{Al}$ addition is as effective as $6 \%$ of $\mathrm{Zn}$ addition [7].

\subsection{Mechanical Tests Evaluation}

3.2.1. Compression Tests. Compression tests were carried out on various prepared brass alloys. The compression results are shown in Table 2 and Figure 8. Brass alloy with $0.31 \%$ $\mathrm{Al}$ addition (Code 2) has a larger compression strength than other cast alloys. The grain size of this alloy, after adding of $0.31 \% \mathrm{Al}$, is larger as compared with both alloys. But the structure turns to be equiaxed containing mainly $\beta$ with $\alpha$ 


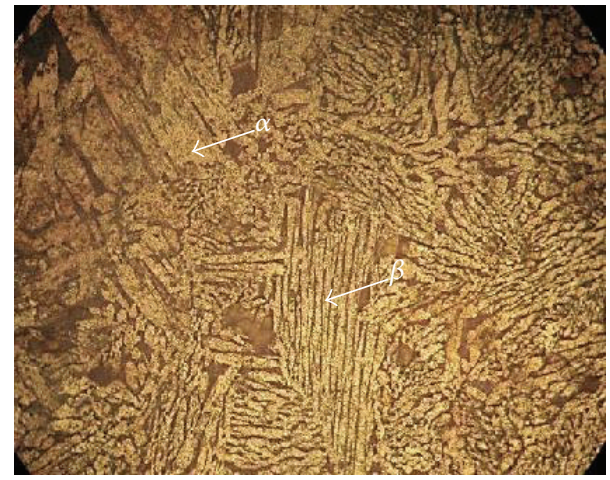

Figure 5: The microstructure of CuZn39Pb3 alloy after addition of $0.54 \% \mathrm{Al}($ Code 4$)$ at $500 \mathrm{x}$.

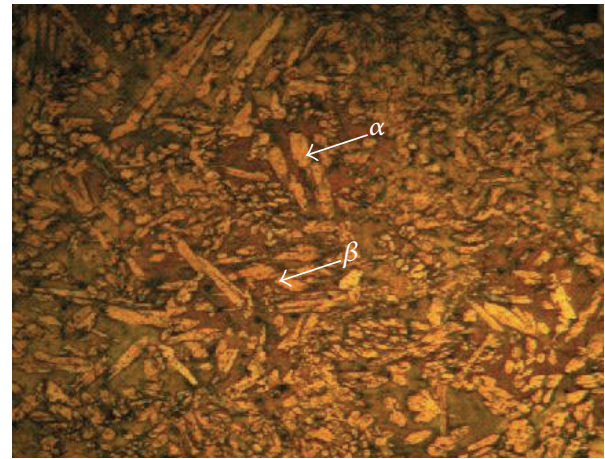

Figure 6: The microstructure of $\mathrm{CuZn} 39 \mathrm{~Pb} 3$ alloy after addition of $0.96 \% \mathrm{Al}$ (Code 5) at 500x.

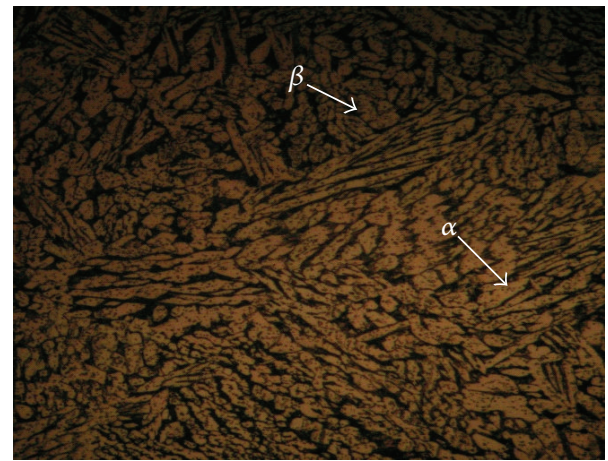

FIgURE 7: The microstructure of CuZn39Pb3 alloy after addition of $0.28 \% \mathrm{Al}$ and $0.93 \% \mathrm{Ti}$ (Code 6 ) at 500x.

needles dispersed within the matrix. So, because of larger $\beta$ phase volume fraction, alloy (Code 2) is acquired a higher compression strength.

Figure 9 shows the difference of the compression results between alloy (Code 1 ) with $0.28 \% \mathrm{Al}$ and alloy (Code 6) with $0.28 \% \mathrm{Al}+0.93 \% \mathrm{Ti}$ additions. The results show that, after the addition of $\mathrm{Ti}$ into the alloy, the compression strength increased more than that in the other one, where maximum compression load is about $101.28 \mathrm{KN}$ with deformation of $4.3962 \mathrm{~mm}$, as compared with $96.56 \mathrm{KN}$ and $4.7875 \mathrm{~mm}$

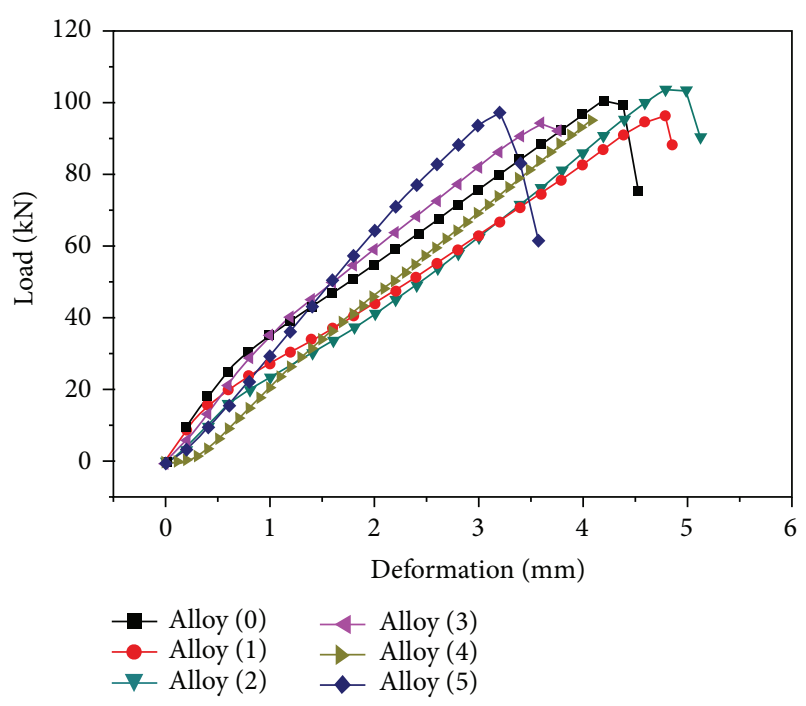

FIgURE 8: The results of compression tests for the studied brass alloys.

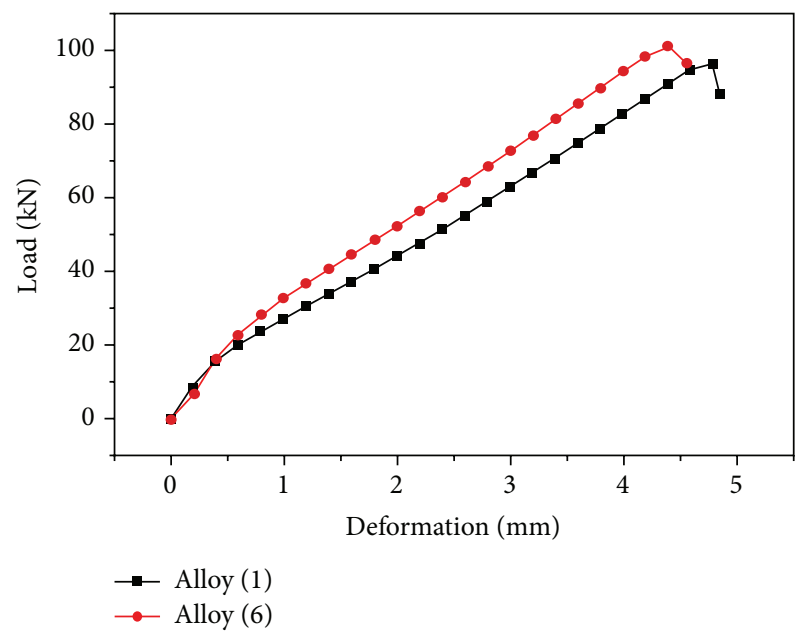

FIGURE 9: The results of compression tests for the studied brass alloys 1 and 6.

for alloy (Code 1) containing $0.28 \% \mathrm{Al}$. This confirms the increment in the compression strength after Ti adding.

Figure 10 shows the relationship between compression strength, hardness, and grain size of $\beta$-phase for the studied brass alloys. From this figure, generally, both of compression strength and Vickers hardness increase with decreasing of the grain size. As a result, increasing of the weight percentage of $\mathrm{Al}$ led to the decrease of the grain size; thus, the gain in mechanical properties of brass alloys was acquired. Higher compression strength was for alloy (Code 2); this is due to the increase of the fraction of $\beta$-phase in alloy containing $0.31 \%$ wt of Aluminum.

3.2.2. Microhardness Tests. The microhardness tests results are shown in Table 2. Also, any important difference was found in hardness. The difference of the mechanical properties between both alloys can be explained because 


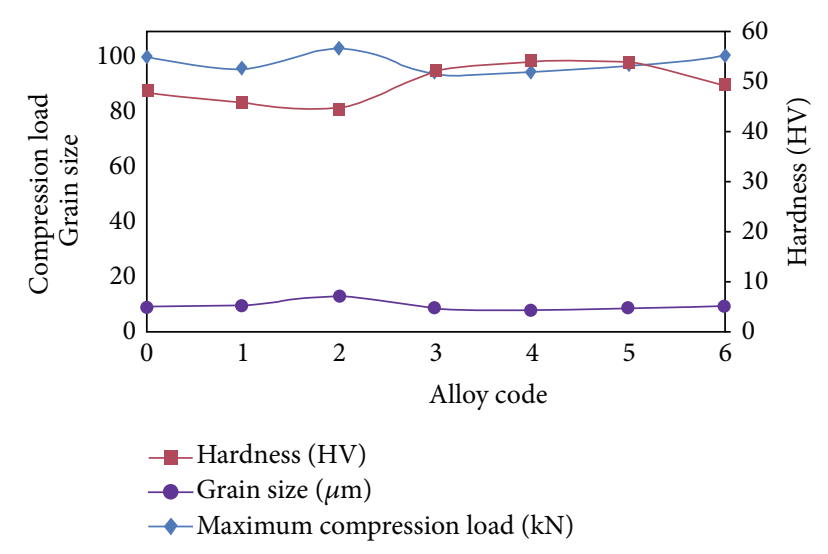

FIGURE 10: The compression strength, Vickers hardness, and grain size for the studied brass alloys.

of the grain refinement of $\beta$-phase, characterized by higher hardness [8] observed in alloys (Codes 3,4 , and 5), as shown in Figure 10. It is obvious that the addition of Ti into alloy (Code 1) containing $0.28 \% \mathrm{Al}$ led to the increase of the hardness value and compression strength of alloy (Code 6), as observed in Table 2.

\section{Conclusions}

The experimental results including the analysis of the prepared brass alloys to study and evaluate the effect of $\mathrm{Al}$ and $\mathrm{Ti}$ alloying elements on microstructure and mechanical properties of $\mathrm{CuZn} 39 \mathrm{~Pb} 3$ alloy show the following.

(i) Aluminum has a significant effect on microstructure; grain size and morphology and mechanical properties; compression strength and hardness of CuZn39Pb3 alloy.

(ii) The microstructure of CuZn39Pb3 alloy is extensively modified by the addition of $\mathrm{Al}$ and $\mathrm{Ti}$.

(iii) Adding of $0.31 \% \mathrm{Al}$ has a larger compression strength as compared with the other alloys.

\section{Conflict of Interests}

The authors declare that there is no conflict of interests regarding the publication of this paper.

\section{References}

[1] H. Imai, Y. Kosaka, A. Kojima et al., "Characteristics and machinability of lead-free P/M Cu60-Zn40 brass alloys dispersed with graphite," Powder Technology, vol. 198, no. 3, pp. 417-421, 2010.

[2] P. García, S. Rivera, M. Palacios, and J. Belzunce, "Comparative study of the parameters influencing the machinability of leaded brasses," Engineering Failure Analysis, vol. 17, no. 4, pp. 771-776, 2010.

[3] D. D. Davies, A Note on the Dezincification of Brass and the Inhibiting Effect of Elemental Additions, Copper Development Association, New York, NY, USA, 1993.
[4] A. Haruiko, I. Hisashi, L. Shufeng et al., "The effect of solid solutionizing Ti element on microstructural and mechanical properties of extruded $\mathrm{Cu}-40 \mathrm{Zn}$-Ti ternary alloy," Transactions of JWRI, vol. 40, no. 1, 2011.

[5] R. Cook, "Grain refinement of aluminum-silicon foundry alloys," in Metallurgy Aluminum, pp. 9-12, London \& Scandinavian Metallurgical Co, London, UK, 1998.

[6] D. H. Herring, "Grain Size and its influence on Materials Properties," The Heat Treat Doctor, dherring@heat.treat.doctor.com.

[7] M. Sadayappan, F. A. Fasoyinu, D. Cousineau et al., "Permanent mold casting of copper base alloys," ICA Project No. TPT-045296, Final Report Phase VI MTL 97-1 (TR-R), 1997.

[8] ASM Handbook: Volume 15: Casting, American Society for Metals, Metals Pack, Ohio, USA, 1988. 

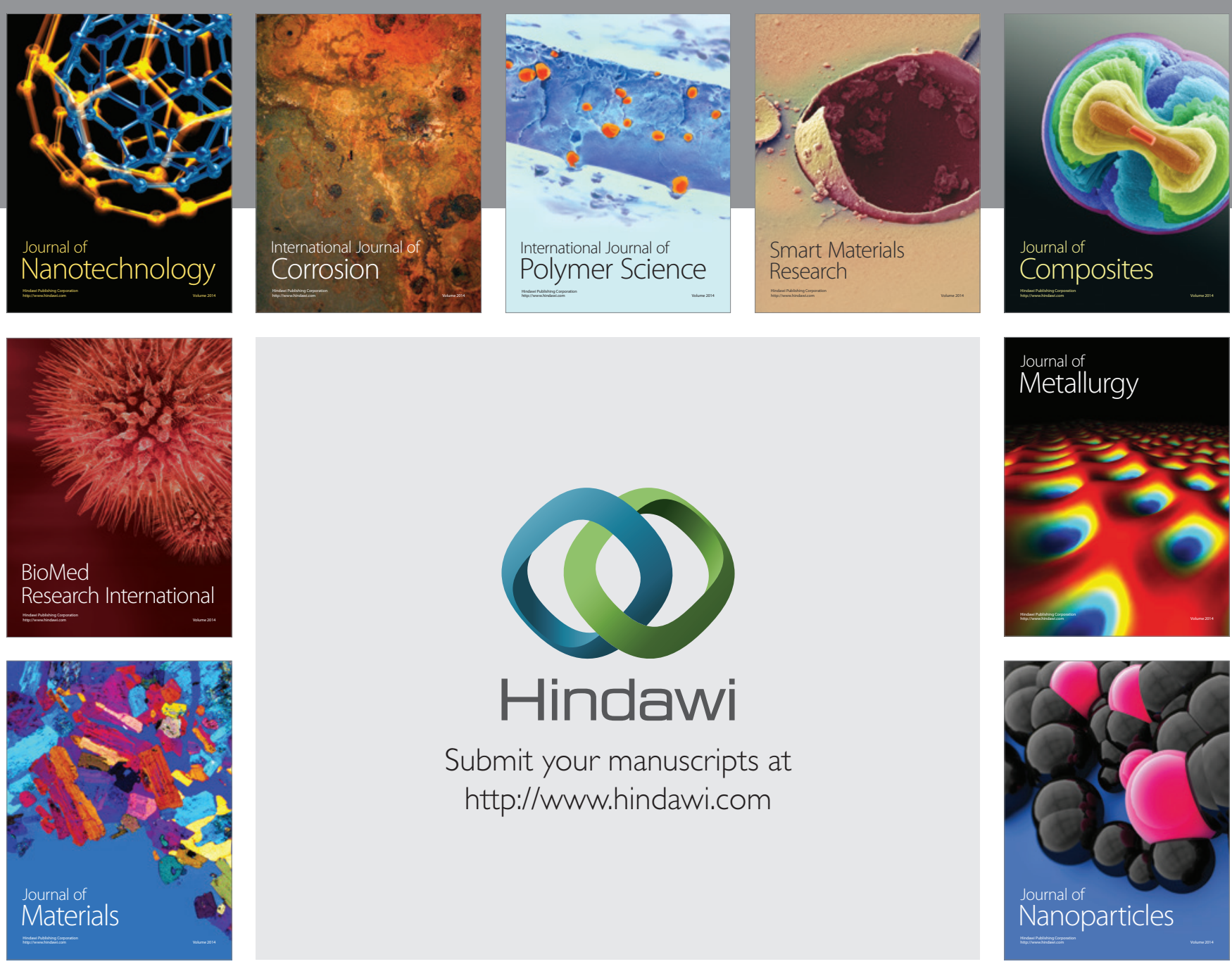

Submit your manuscripts at http://www.hindawi.com
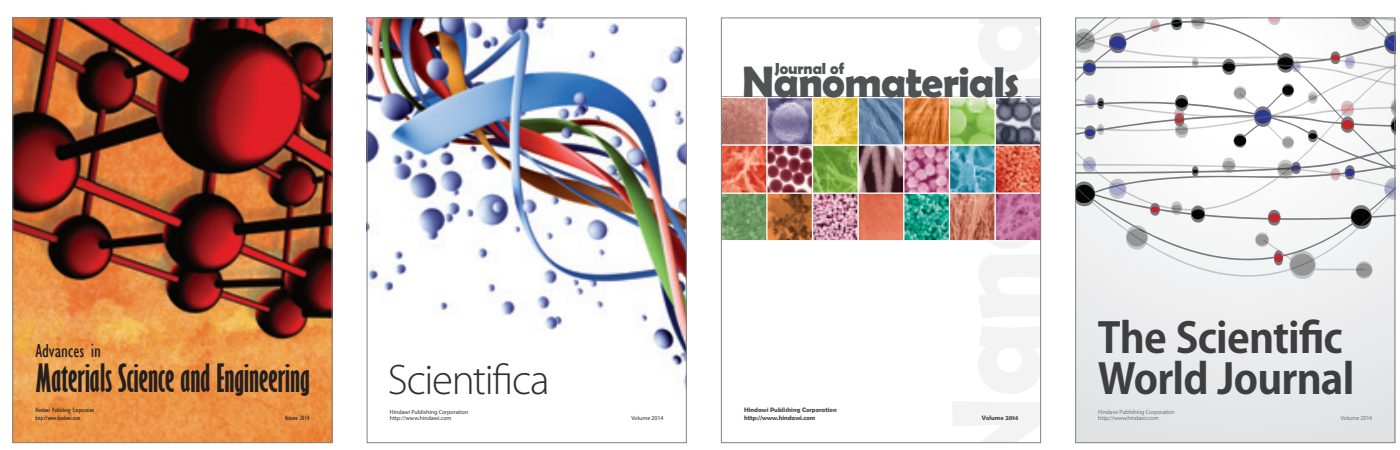

\section{The Scientific World Journal}
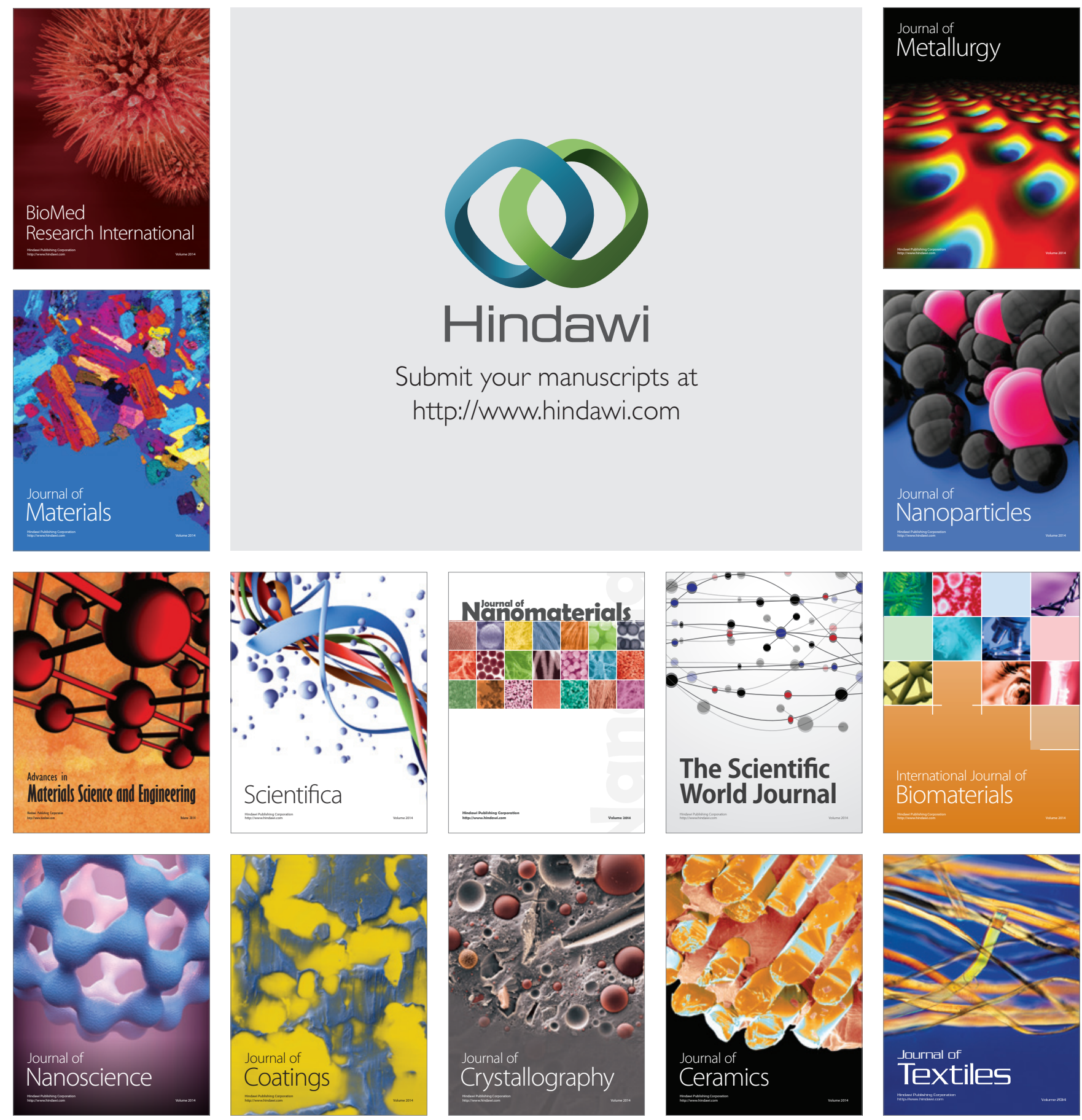